\title{
Management of penetrating stab wounds of the chest: an assessment of the indications for early operation
}

\author{
F A SANDRASAGRA \\ From the General Hospital, Colombo, Sri Lanka
}

\begin{abstract}
Sandrasagra, F A (1978). Thorax, 33, 474-478. Management of penetrating stab wounds of the chest: an assessment of the indications for early operation. Haemothorax, haemopneumothorax, and pneumothorax were the most common complications in 85 patients with penetrating stab injuries of the chest. These complications were amenable to conservative treatment by aspiration or drainage of the pleural space. Immediate operation was indicated in $\mathbf{3 0}$ cases. Indications for surgery were haemorrhage from a major systemic or pulmonary vessel or the heart, cardiac tamponade, diaphragmatic penetration, oesophageal and bronchial tears, and sucking chest wounds. The need for immediate operation was clinically obvious at presentation in most cases. It should have been suspected from the situation of the entry wound, the nature of the weapon used, the size of the haemothorax, and the clinical findings in the others. All 11 deaths occurred in that group in which early operation was indicated, and some could have been averted had the need for operation been suspected early. Seven patients developed an empyema; five were in the group that required immediate surgery and in the other two infection occurred in a clotted haemothorax. Early repair of the associated visceral injuries and complete evacuation of a haemothorax, either fluid or clotted, could reduce the incidence of empyema.
\end{abstract}

The efficacy of conservative management of penetrating chest injuries by aspiration or drainage of collections of air or blood in the pleural cavity was established in the second world war, and confirmed by subsequent experience in Korea (Valle, 1952; King and Harris, 1953), Vietnam (Virgilio, 1970), and in civilian practice (Cordice and Cabezon, 1965; Beall, et al, 1966). Penetrating stab wounds of the chest are less destructive than combat injuries and respond well to conservative treatment (Stein and Schnier, 1965). Some of these patients, however, need early operation to control haemorrhage or repair damaged internal organs. Failure to recognise this category of patient early may be fatal. A knowledge of the weapon used, the site of the entry wound in relation to the underlying structures, the clinical state of the patient, and the total blood loss could serve to distinguish those who need early operation from those who could be managed conservatively.

\section{Patients}

Stab wounds accounted for 85 of the 100 penetrating chest injuries that I saw in Sri Lanka between
1969 and 1973. The ages of the victims ranged from 14 to 55 , with a peak incidence between 20 and 30 . All but three were men. One stab wound was accidentally inflicted by the pointer of a weighing scale, another was self-inflicted with suicidal intent, and the rest were caused by criminal assault with various weapons.

\section{Type of weapon}

The kris knife (fig 1) was the popular weapon and accounted for 55 injuries. This weapon has a blade length of 4-9 inches and a width of $\frac{1}{4}-\frac{1}{2}$ inch. A $\tilde{O}$ pointed knife (fig 2) with dimensions similar to a kris knife caused 10 wounds. Penknives and table knives were each used in four cases. There was 0 one instance each of stabbing with a weighing $\mathbb{D}$

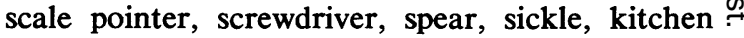
knife, and "katty" (fig 3). The weapon used in six cases was not documented.

\section{Distribution of entry wounds}

Left-sided stab wounds were two and a half times more frequent than right-sided ones. Fifty-three 


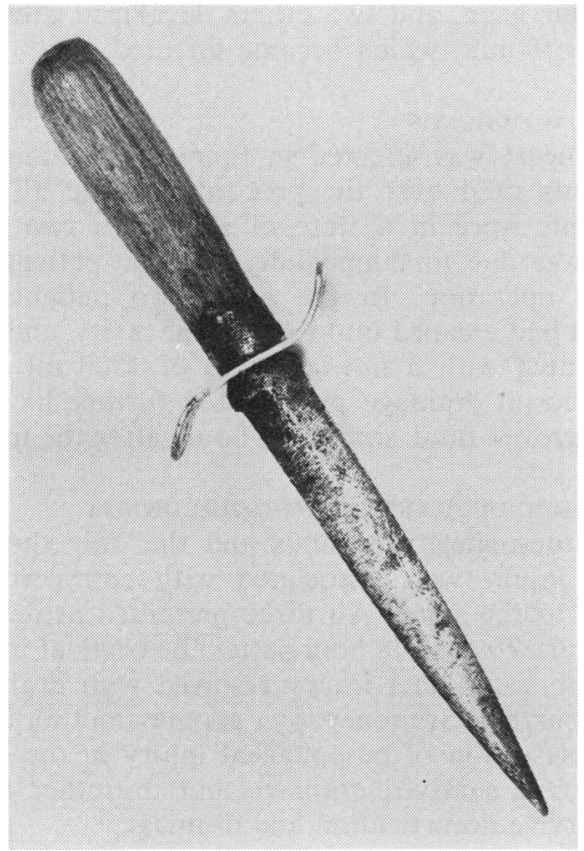

Fig 1 Kris knife (dagger).

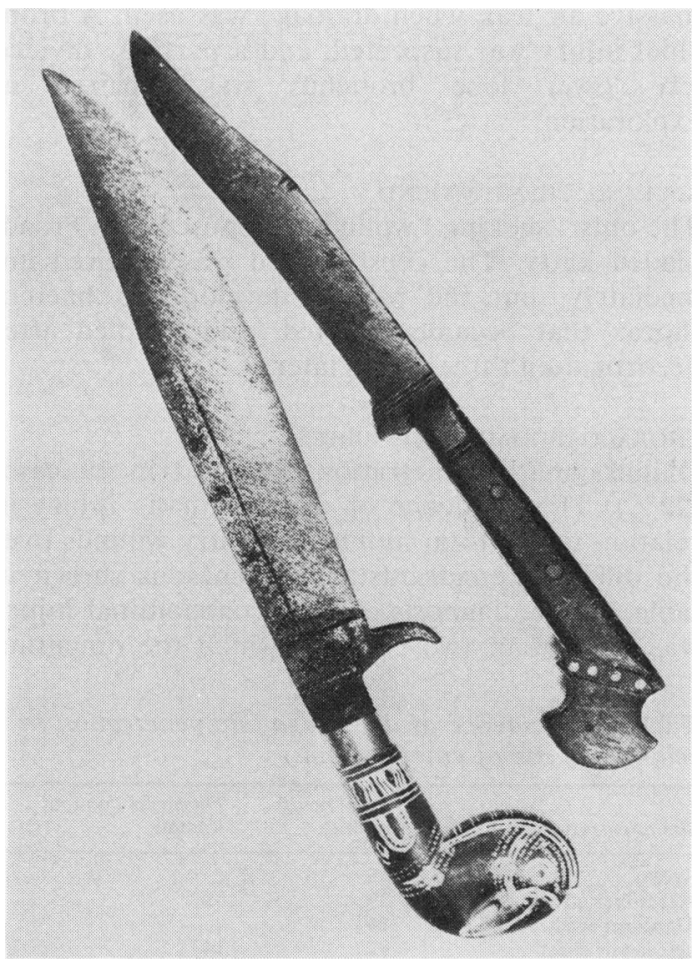

Fig 2 Pointed knives.

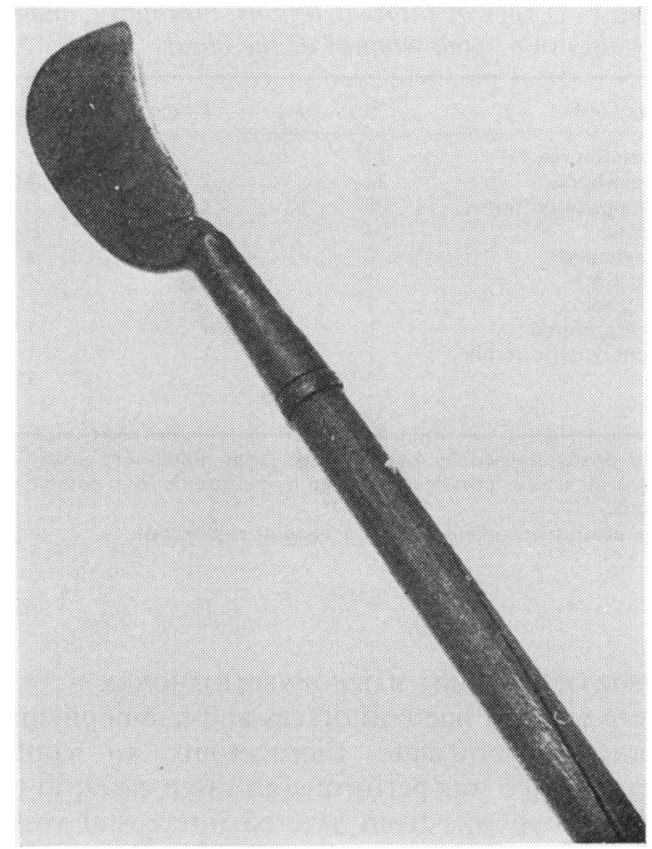

Fig 3 Katty.

entry wounds were posterior to the mid-axillary line. The entry wounds were equally distributed between the upper and lower halves of the chest, and five were in the supraclavicular region and the neck. An exit wound was present in only one case. Additional superficial stab wounds over the other parts of the body were found in 39 patients. There were separate penetrating abdominal stab wounds in three cases. Multiple stab wounds of the same hemithorax and bilateral chest injuries were seen in two patients each.

\section{Clinical features, treatment, and results}

Chest pain, shortness of breath, surgical emphysema, and abdominal pain were the dominant presenting features. Thirteen patients were in a state of "shock" (pulse rate $>100 / \mathrm{min}$ and blood pressure $<80 \mathrm{mmHg}$ ). This was caused by haemorrhage in 11 and cardiac tamponade in the other two. The different types of thoracic lesions met with are summarised in table 1.

\section{PNEUMOTHORAX}

A pneumothorax was three times more common with wounds of the upper chest than with those over the lower half. All 14 pneumothoraces were treated by apical intercostal tube drainage without any complications. 
Table 1 Types of thoracic lesions, morbidity, and mortality in 87 stab wounds of the chest

\begin{tabular}{llll}
\hline Type of lesion & No of cases & Empyema & Deaths \\
\hline Pneumothorax & 14 & 2 & \\
Haemothorax & 32 & 1 & $4^{*}$ \\
Haemopneumothorax & 26 & 2 & 3 \\
Cardiac & 4 & & 1 \\
Oesophageal & 2 & 1 & \\
Bronchial & 1 & 1 & 1 \\
Chylothorax & 1 & 7 & $1 \dagger$ \\
Sucking wound & 1 & 11 \\
Diaphragmatic hernia & 1 & & \\
Nil & 5 & & \\
Total & 87 &
\end{tabular}

*Two deaths caused by haemorrhage from pulmonary artery and intercostal artery. Two deaths caused by peritonitis from colonic stab wounds.

†One death from splenic wound missed at exploration.

HAEMOTHORAX AND HAEMOPNEUMOTHORAX

There were 58 haemothoraces and haemopneumothoraces. Immediate thoracotomy to control haemorrhage was performed in three cases; in two the bleeding was from severed intercostal vessels and in the third the right pulmonary artery had been injured and the patient died. Two others were explored for suspected cardiac and thoracoabdominal wounds, and a sixth case had a transthoracic exploration for a thoracoabdominal injury. Thirteen haemothoraces were aspirated without complication, and the other 39 were treated by intercostal tube drainage. Reactivation of bleeding from a severed intercostal artery 24 hours after the injury when drainage was instituted resulted in the death of one patient. Another two patients died of associated colonic injuries. Three cases developed an empyema. In one it supervened on a thoracoabdominal injury with peritonitis, and infection in a clotted haemothorax accounted for the other two. All three patients needed decortication.

The size of the haemothorax was measured at the time of aspiration, drainage, or operation in all the patients and was below $1000 \mathrm{ml}$ in 53 . Only six of the patients with a haemothorax of less than $1000 \mathrm{ml}$ presented in a state of shock, which was caused by a combination of intrathoracic and intra-abdominal bleeding in three of them. Both patients who underwent surgery for severed intercostal arteries were in this group, and the only empyema complicating a haemothorax of this size was in a patient with a thoracoabdominal injury. Both deaths in this group were due to colonic wounds. Three of the five patients with a haemothorax of over $1000 \mathrm{ml}$ were in a state of shock. Two died from intercostal and pulmonary arterial haemorrhage, and two others developed a clotted haemothorax, which became infected.

\section{CARDIAC WOUNDS}

The heart was affected in four of the nine stab wounds sited over the precordium, and all four patients were in a state of shock. In two cases. this was due to tamponade, and one patient sur- $\vec{\omega}$ vived operation. In the other two patients the ${ }^{\circ}$ blood had escaped into the pleural cavity, and they $\vec{x}$ presented with a haemothorax of $1500 \mathrm{ml}$ each. $\underset{\omega}{\omega}$ Intercostal drainage precipitated further bleeding that proved fatal, six and $\mathbf{1 3}$ hours after the injury.

\section{THORACIC DUCT AND OESOPHAGEAL INJURY}

Both oesophageal wounds and the only thoracic duct injury were associated with entry wounds close to the spine. All three presented as delayed of pleural effusions 48 hours after the original injury. क The thoracic duct injury resolved with drainage. $\vec{\varphi}$ A recurrent Gram-negative pyopneumothorax led to a suspicion of oesophageal injury in the other two. One survived drainage, but the other failed to survive decortication and drainage.

\section{BRONCHIAL INJURY}

A posterior stab wound was associated with a massive air leak when drainage was used. A bronchial injury was suspected, and a partially divided left lower lobe bronchus was repaired at exploration.

\section{SUCKING CHEST WOUND}

The only "sucking" wound was caused by a broadbladed katty. The chest wound was repaired immediately, but the patient developed a haemothorax that became infected, and he died after decortication three weeks later.

\section{THORACOABDOMINAL INJURIES}

Diaphragmatic penetration occurred in 19 cases $(22 \%)$. The incidence of diaphragmatic injury in $N$ relation to the total number of entry wounds over $N$ the different quadrants of the chest is shown in table 2 . The diagnosis of thoracoabdominal injury $\mathrm{\omega}$ was obvious in two cases in which the omentum

Table 2 Incidence of diaphragmatic penetration in relation to site of entry wound

\begin{tabular}{lcc}
\hline Site of entry wound & $\begin{array}{l}\text { Total no of } \\
\text { wounds }\end{array}$ & $\begin{array}{l}\text { Thoracoabdominal } \\
\text { wounds }\end{array}$ \\
\hline Neck & 5 & \\
Left upper chest & 27 & 3 \\
Right upper chest & 14 & 14 \\
Left lower chest & 32 & 2 \\
Right lower chest & 9 & \\
\hline
\end{tabular}


was found to protrude through the chest wound. Abdominal signs were present in 14 cases, but in five cases in which the injury was either confined to the lesser sac or in which there was no visceral damage abdominal signs were absent. Three patients were in a state of shock due to a combination of intrathoracic and intra-abdominal bleeding. A haemothorax or haemopneumothorax was associated with 14 thoracoabdominal injuries. In only one case, where a broad kitchen knife had been the offending weapon, was there a diaphragmatic hernia.

The abdominal injuries were dealt with via a thoracotomy in three cases and via a laparotomy in the rest. The associated haemothorax in the latter group was treated by aspiration or drainage. Two empyemas developed in this group, and four patients died. Both patients with colonic wounds died. One was not seen until 48 hours after the injury. An exit wound in the posterior wall of the transverse colon that was missed at the original exploration was responsible for the fatal outcome in the second case. A splenic wound overlooked at exploration accounted for the third death. The fatal diaphragmatic hernia too was seen late due to transport difficulties and peritonitis was established at the time of repair.

In four thoracoabdominal stab wounds the knife had passed through the diaphragm directly from the lower chest wall, and no intrapleural injury could be' discerned. One patient presented with a table knife sticking out of his chest. He had had a previous decortication for an empyema and did not have any intrathoracic complications.

\section{Discussion}

Pneumothorax, haemothorax, and haemopneumothorax were the commonest complications of stab wounds of the chest and accounted for $83 \%$ of the thoracic complications. A pneumothorax may be treated expectantly if it is small and causing no symptoms. Early pulmonary expansion can be achieved by inserting an apical intercostal drain and is indicated if over $20 \%$ of the lung is collapsed. The technique of evacuating a haemothorax is controversial. Intercostal drainage increases the tendency to infection (Valle, 1952; Gray et al, 1960). The fact that three empyemas occurred in 39 cases subjected to intercostal tube drainage appears to support this argument. One empyema complicated a thoracoabdominal injury, and the other two supervened on a clotted haemothorax. Needle aspiration would not have averted these complications. Either technique is equally effective as long as the evacuation is com- plete and not delayed (Cordice and Cabezon, 1965; Beall et al, 1966).

The site of drainage for a haemopneumothorax was determined by the relative amounts of air leak and blood loss as judged by the height of the fluid level and degree of lung collapse on the plain chest radiograph. If the air leak was dominant an apical intercostal tube was placed; if the fluid level was high a basal tube was inserted. As early and complete pulmonary expansion forms the basis of conservative treatment of chest injuries, both apical and basal tubes were used for a haemopneumothorax in which the blood loss was over $500 \mathrm{ml}$, and there was also a significant air leak.

A small percentage of patients with a haemothorax have a haemorrhage from a major systemic or pulmonary vessel or heart. Some of them may be in extremis at presentation, and thoracotomy is indicated as an urgent measure. In the others the clinical state may stabilise with transfusion until further bleeding occurs. This experience suggests that if the initial drainage exceeded $1000 \mathrm{ml}$ there was a greater likelihood of a major vascular injury and a greater tendency for the blood to clot within the pleural cavity. Thoracotomy is therefore advised in stab wounds when the initial drainage from a haemothorax exceeds $1000 \mathrm{ml}$. The intercostal vessels are at risk in stab wounds at right angles to a rib, and the internal mammary artery is liable to injury in parasternal stab wounds. Thoracotomy should be considered with entry wounds in these areas even if the initial blood loss is less than $1000 \mathrm{ml}$. Stab wounds over the precordium are serious, and in four out of nine such wounds $(44 \%)$ the heart had been penetrated. Diagnosis is easy if one suspects the possibility of cardiac tamponade. When the blood escapes into the pleural cavity the clinical presentation is of a haemothorax. The size of the haemothorax, if over $1000 \mathrm{ml}$, should point to a major vascular injury and warrant thoracotomy.

The oesophagus and thoracic duct are protected by the spine but may be damaged in obliquely directed stab wounds alongside the spine. A delayed or recurrent effusion indicates a thoracic duct or oesophageal leak. The former injury may resolve with drainage. If the leak persists the thoracic duct must be ligated early before large fluid and electrolyte losses occur. As the outcome in oesophageal wounds depends on early repair, contrast studies of the oesophagus are indicated in all penetrating wounds of the posterior mediastinum.

A massive air leak indicates a major bronchial injury. The diagnosis can be confirmed by bronchoscopy, and repair is indicated. A sucking chest 
wound follows the use of a weapon with a broad blade and needs immediate closure. The possibility of diaphragmatic injury must be borne in mind in all penetrating chest wounds, particularly in stab wounds of the left lower chest. The diagnosis of a penetrating thoracoabdominal injury is a clinical one and depends on the presence of abdominal signs in a chest injury. Abdominal signs may be referred features of a haemothorax or pneumothorax. The disappearance of the abdominal signs on evacuation of the pleural space serves to distinguish a purely thoracic injury from a thoracoabdominal wound (Cordice and Cabezon, 1965). The referred abdominal signs of a thoracic injury may, however, not disappear immediately upon evacuation of the pleural space. Thus four of the 85 patients had negative laparotomies for persistent abdominal signs despite pleural drainage. On the other hand, abdominal signs may be minimal or even absent when diaphragmatic penetration is unaccompanied by a visceral injury or in injuries confined to the lesser sac. Diaphragmatic herniation is uncommon with stab wounds on account of the narrow width of the weapon used. The thoracic component of a thoracoabdominal stab wound can usually be treated conservatively and the abdominal injury dealt with through an abdominal incision. Thoracotomy is necessary only if gross pleural soiling from the peritoneal cavity occurs. The mortality in a thoracoabdominal injury is determined by the intra-abdominal lesions and not the thoracic component of the wound.

Chest injuries that need immediate surgery for arrest of haemorrhage or repair of damaged viscera are associated with a higher mortality than those that can be managed conservatively (Kish et al, 1976). The mortality for a series of stab wounds of the chest is directly proportional to the percentage of cases needing immediate operation. Of 131 stab wounds reviewed by Hegarty (1976), there were two thoracoabdominal wounds and one cardiac injury. The mortality for his series was $1.6 \%$. Owing to the high incidence of thoracoabdominal, cardiac, and oesophageal wounds in this series of 85 patients, immediate surgery was indicated in 30 cases (table 3$)$. Five $(21 \%)$ of the 23 cases that were operated on shortly after the injury had occurred died. On the other hand, when operation was indicated and the treatment was either conservative or delayed, there were six deaths $(85 \%)$ in seven patients, some of which could have been averted had surgical intervention been prompt. The problem of managing penetrating stab wounds of the chest consists of distinguishing those cases that can be managed conservatively from those that need prompt $\stackrel{\circ}{\frac{7}{0}}$ surgical intervention. This problem could be re- $\frac{D}{\partial}$ solved with a high index of suspicion, a knowledge $\frac{\bar{\sigma}}{\bar{c}}$ of the weapon used, the site of the entry wound, $\widetilde{\Phi}$ the clinical state of the patient, and the magnitude of the blood loss.

Table 3 Indication for operation, method of treatment, and results in 30 cases that needed early operation. Number of deaths in parentheses

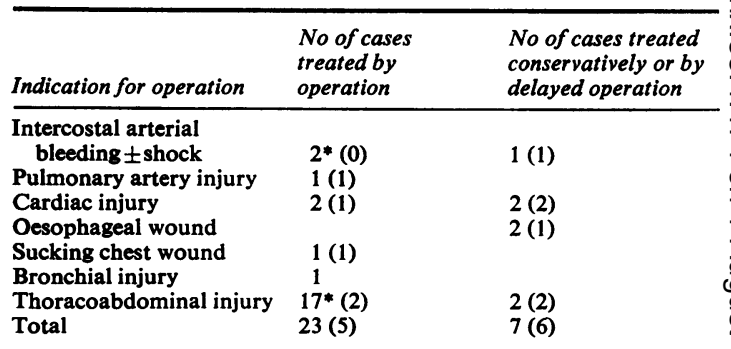

* One case with a thoracoabdominal injury with intercostal arterial haemorrhage.

\section{References}

Beall, A C, Crawford, $\mathrm{H} \mathrm{W}$, and De Bakey, $\mathrm{M} \mathrm{E}$ (1966). Considerations in the management of acute traumatic hemothorax. Journal of Thoracic and $\frac{\mathrm{D}}{\mathrm{D}}$ Cardiovascular Surgery, 52, 351-358.

Cordice, J W V, and Cabezon, J (1965). Chest trauma $\vec{\circ}$ with pneumothorax and hemothorax. Review of 3 experience with 502 cases. Journal of Thoracic and Cardiovascular Surgery, 50, 316-353.

Gray, A R, Harrison, W H, Couves, C M, and Howard, J M (1960). Penetrating injuries to the chest. Clinical results in the management of $769 \frac{\mathrm{O}}{3}$ patients. Amercan Journal of Surgery, 100, 709714.

Hegarty, M M (1976). A conservative approach to penetrating injuries of the chest. Experience with 131 successive cases. Injury, 8, 53-59.

King, J D, and Harris, J H (1953). War wounds of $ᄋ$ the chest among marine and naval casualties in Korea. Surgery, Gynecology and Obstetrics, 97, 을 199-212.

Kish, G Kozloff, L, Joseph, W L, and Adkins, P Cỗ (1976). Indications for early thoracotomy in the $N$ management of chest trauma. Annals of Thoracic N Surgery, 22, 23-28.

Stein, A, and Schnier, G (1965). Penetrating stabo wounds of the chest. South African Medical Journal, $39,548-552$.

Valle, A R (1952). Management of war wounds of the $\stackrel{\mathcal{D}}{?}$ chest. Journal of Thoracic Surgery, 24, 457-481. T

Virgilio, R W (1970). Intrathoracic wounds in battle casualties. Surgery, Gynecology and Obstetrics, 130, $\overrightarrow{\mathrm{d}}$ 609-615.

Requests for reprints to: Mr F A Sandrasagra, Department of Cardiothoracic Surgery, Broadgreen $\Omega$ Hospital, Thomas Drive, Liverpool 14. 